\title{
Restoration of Natural Frequency of Cracked Cantilever Beam Using CNT Composite Patch: A Finite Element Study
}

\author{
Mahmoud Nadim Nahas and Mahmoud Ali Alzahrani \\ Mechanical Engineering Department, King Abdulaziz University, P.O. Box 80204, Jeddah 21589, Saudi Arabia \\ Correspondence should be addressed to Mahmoud Nadim Nahas; mnahas@kau.edu.sa
}

Received 16 September 2013; Revised 21 October 2013; Accepted 1 November 2013

Academic Editor: Dumitru Baleanu

Copyright (c) 2013 M. N. Nahas and M. A. Alzahrani. This is an open access article distributed under the Creative Commons Attribution License, which permits unrestricted use, distribution, and reproduction in any medium, provided the original work is properly cited.

\begin{abstract}
Cyclic loadings cause fatigue to the elements of machines leading to crack initiation and propagation. This phenomenon decreases the age of the elements. In particular, cracks decrease the stiffness of the parts and lower the parts natural frequency, leading to failure under normal working conditions. This paper introduces a new application to carbon nanotube (CNT) composites in the repairing process of a cracked specimen to restore the natural frequency of the specimen. Commonly, patches are made of high strength and high stiffness materials. This paper shows that even low stiffness materials, such as epoxy reinforced with CNT, can contribute to the repair of a cracked specimen. A 2D finite element (FE) simulation is used to study the effects of bonding CNT composite patches over the crack location to repair cracked metal specimens. The effects of the patch thickness, length, and CNTs weight concentration ratio are investigated. Results showed an increase in the natural frequency of $31 \%$ compared to the cracked specimen at a crack depth of $70 \%$ of the beam depth and at a distance of $20 \%$ of the total beam length from the support.
\end{abstract}

\section{Introduction}

Vibrational faults in machines are of major concern in the engineering filed. In machines, cracked parts due to fatigue loading can cause a drop in the part natural frequency. This drop can lead to resonant vibrations under normal loading conditions, which may cause failure to the part. A lot of work had been conducted on the change in the natural frequency of a cracked beam compared to a healthy beam. Khaji et al. [1] constructed a closed form analytical solution to the change in the natural frequency of a cracked uniform beam. The crack was molded using a massless, linear, elastic, and rotational spring under six different boundary conditions and different parameters (such as crack location and crack depth). Kim and Stubbs [2] and Lee [3] conducted an experimental work on the detection of crack locations and its size by relating the fractional changes in the natural frequency of the cracked beam to the healthy beam due to the presence of cracks. Zheng and Kessissoglou [4] studied the free vibration of a cracked beam using the finite elements analysis (FEA) to obtain the natural frequencies and mode shapes of the beam. Loya et al. [5] studied the natural frequency of simply supported cracked Timoshenko beam by modeling the cracked region with a massless torsional and normal spring (for the vertical displacement and rotational displacement). Zhong and Oyadiji [6] constructed an analytical model to help in the prediction of the natural frequencies of a cracked simply supported beam with a stationary roving mass. The roving mass helps in detecting the presence of cracks by roving the mass from one end of the beam to another. Since cracks cause a reduction in the stiffness of the beam, this causes a reduction in the beam natural frequency when the roving mass is located near the crack. Matbuly et al. [7] studied the natural frequency of a functionally graded cracked beam resting on a Winkler-Pasternak foundation using the line spring model for formulating and applying the method of differential quadrature to solve it. For the strength of bonded patches, much research had been conducted, with different materials, to evaluate its effectiveness under various conditions. Osnes et al. [8] had studied the strength of bonded joints using the traditional strength of materials approach, which did not agree with experimental results, and inelastic 
TABLE 1: Mechanical properties of epoxy and aluminum specimens.

\begin{tabular}{lccccc}
\hline $\begin{array}{l}\text { Mechanical } \\
\text { properties }\end{array}$ & \multirow{2}{*}{ Steel } & \multicolumn{4}{c}{ Epoxy } \\
\hline$E(\mathrm{GPa})$ & 210 & 3.11 & 4.2 & 4.7 & 4.98 \\
$\nu$ & 0.3 & 0.35 & 0.3492 & 0.3476 & 0.3468 \\
$\rho\left(\mathrm{Kg} / \mathrm{m}^{3}\right)$ & 7860 & 1170 & 1181 & 1191 & 1202 \\
\hline
\end{tabular}

fracture mechanics, which showed good agreement with the experimental results. Hosseini-Toudeshky et al. [9] studied how the curing temperature affects the residual stresses in fiber metal laminate (FML) patches, which showed no effect on the repairing process for the cracked panels. Nahas [10] performed an experimental investigation on the repairing effects of fiber composite patches on the fatigue life of a cracked aluminum specimen. Ariaei et al. [11] used piezoelectric patches to repair cracked beams by applying an external voltage to actuate the piezoelectric patches bonded on the beam. Then the patches reduce the singularity produced by the crack tip. This helped in decreasing the maximum deflection of the beam, due to the reduction of the beam stiffness, to approach the maximum deflection of a healthy beam. Brown et al. $[12,13]$ used self-healing epoxy matrix composite that incorporates healing agent to hinder fatigue cracks. Self-healing was also used by Blaiszik et al. [14] and Williams et al. [15].

In this paper, a FEA is conducted to examine the repair of the natural frequency of a cracked steel beam (at different locations and depth) by adhesively bonding an epoxy patch (with and without multiwalled carbon nanotubes (MWCNTs) reinforcement). The properties of the steel specimen, epoxy, and multiwalled carbon nanotubes (MWCNTs) are discussed in Section 2. The modeling of the parts and the boundary conditions are discussed in Section 3. The FEA results of the analysis are summarized in Section 4. Discussions of the results are given in Section 4 and conclusions of the results are given in Section 5.

\section{Mechanical Properties}

CNTs are known for their high mechanical properties [16]. They have shown great potential in the reinforcement of composite materials. Many research works were carried out to predict the mechanical properties of CNT reinforced composite [17-22]. Omidi et al. [23] experimented on the effects of adding MWCNTs into an epoxy patch on Young's modulus and strength of the CNT/Epoxy composite. These results were used with the work done by Rokni et al. [24, 25] to construct a finite elements model to determine the optimum distribution of CNTs to obtain the highest natural frequency in a microbeam. Different weight percentage (wt.\%) of CNTs was used (from $0.5 \%$ to $10 \%$ ). The mechanical properties used in this paper (Young's modulus $E$, density $\rho$, and Poisson's ratio) of the epoxy patch (with different wt.\% of CNTs) and the steel specimen are shown in Table 1.

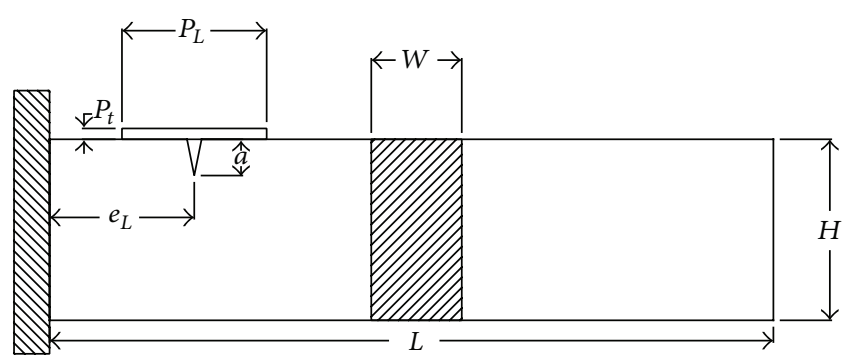

Figure 1: Beam dimensions.

\section{Modeling and FE Idealization}

A 2D plane stress FE model was constructed in ABAQUS/Standard with dimensions similar to those in [1] and was verified with the results in the literature. Figure 1 shows the dimensions of the beam used in the FE analysis where $L$ is the beam length which is $100 \mathrm{~mm}, H$ is the beam depth which is $25 \mathrm{~mm}$, and $W$ is the beam width which is $12.5 \mathrm{~mm}$. The ratio $\mathrm{a} / \mathrm{H}$ (the ratio of the crack depth to the beam depth) was taken as 0.7 and the crack position $e_{L}$ was taken at a location of $20 \%$ of the beam total length away from the support location. These values, according to [1], show large decrease in the beam original natural frequency compared to the other values used in the work. The epoxy patch has a length of $P_{L}$ and thickness of $P_{t}$.

Figure 2 shows the FE models and the boundary conditions used in the analysis. The nodes to the left end were constrained from movement in the $x$ and $y$ directions, while the nodes to the right end were left unconstrained. An 8-node quadrilateral element was used in the model. The repair of the natural frequency was investigated under different patch thickness and length $\left(P_{t}\right.$ and $\left.P_{L}\right)$ values with different CNT wt.\% (2 wt. $\%, 4$ wt. $\%$ and 6 wt.\%). $P_{t}$ values were taken from 0.5 to $3 \mathrm{~mm}$, while $P_{L}$ was taken from 10 to $30 \mathrm{~mm}$. Then the effects of the crack depth and location were investigated when $P_{t}$ was $1.5 \mathrm{~mm}$ and $P_{L}$ was $20 \mathrm{~mm}$.

\section{Results and Discussions}

The first natural frequency was obtained for the model of the original beam (the uncracked beam), and then a crack with a value of $a / H=0.7$ and $e=0.2$ was introduced. The natural frequency was then obtained from ABAQUS for the cracked beam, firstly without the epoxy patch and then with the epoxy patch. Figure 3 shows the FE contour plot of the first mode shape of the beam. The epoxy patch was added to the model at different $P_{t}$ values $(0.5,1,1.5,2,2.5$, and $3 \mathrm{~mm})$. Figure 4 shows the graph of the increase of natural frequency of the cracked beam with different $P_{t}$ and CNT wt.\%. The graph shows that, with the increase of the patch thickness, more repairing is observed in the natural frequency of the patched cracked beam in comparison to the unrepaired beam. A patch thickness of $3 \mathrm{~mm}$ increased the natural frequency of the cracked beam by $41 \%$ at $6 \mathrm{wt} . \% \mathrm{CNT}$, but the increase in $P_{t}$ can lead to stress concentrations, so $P_{t}$ was taken as $1.5 \mathrm{~mm}$ for the rest of the analysis. 


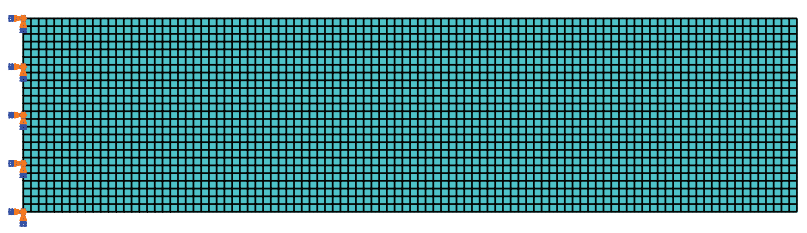

(a)

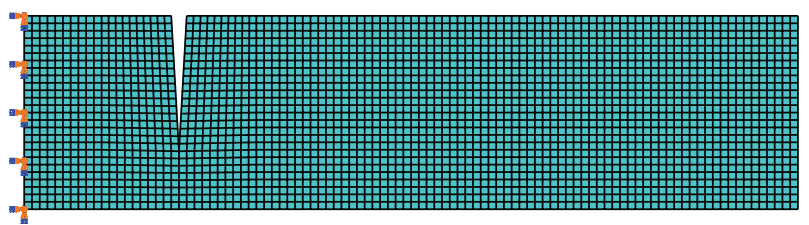

(b)

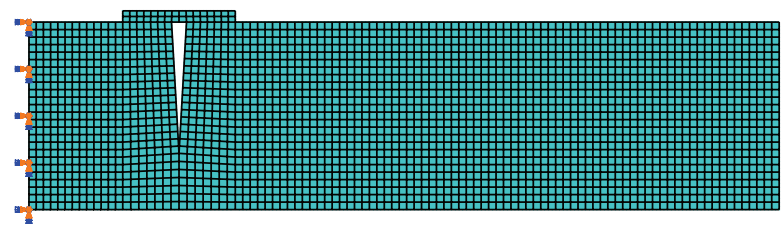

(c)

Figure 2: FE model boundary conditions, (a) original beam, (b) cracked beam, and (c) epoxy patched beam.

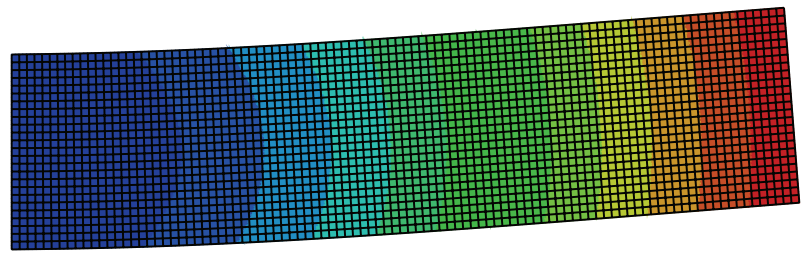

(a)

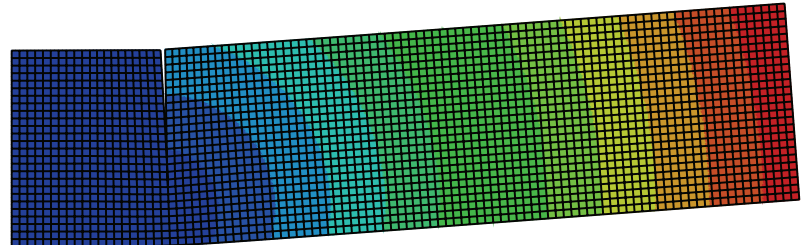

(b)

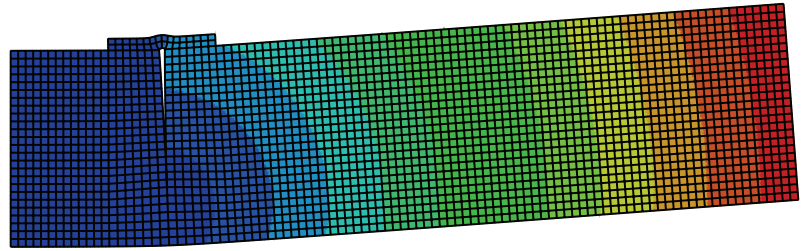

(c)

FIGURE 3: FE first mode shape contour plot, (a) original beam, (b) cracked beam, and (c) epoxy patched beam.

Different $P_{L}$ values $(10,15,20,25$, and $30 \mathrm{~mm})$ were used in order to investigate the effects of the patch length on the increase in the natural frequency of the beam. Figure 5 shows that $P_{L}$ has no effect on the increase in the natural frequency of the cracked beam. Only CNT's concentration increased the natural frequency, but short length patches are weaker than

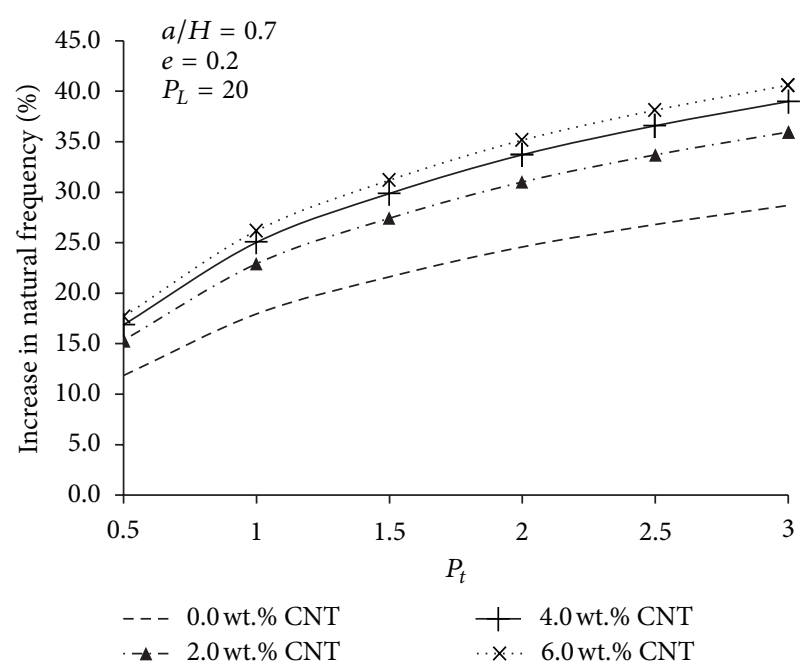

FIGURE 4: Increase in cracked beam natural frequency with different $P_{t}$ and wt.\% of CNT.

long ones, due to the small interfacial area between the patch and the beam, so $P_{L}$ was taken as $20 \mathrm{~mm}$ in further analysis.

To investigate the changes in the natural frequency of the cracked beam with the repairing patch at different crack depths $(a / H)$ and crack locations $(e)$, a patch with $P_{t}=$ $1.5 \mathrm{~mm}$ and $P_{L}=20 \mathrm{~mm}$ was used. $a / H$ was changed from $20 \%$ to $70 \%(0.2,0.35,0.5,0.6$, and 0.7$)$ and $e$ from $20 \%$ to $80 \%(0.2,0.4,0.5,0.6$, and 0.8$)$. Figure 6 shows the relative natural frequency of the cracked beam with and without CNT composite patches at different crack depths. It is clear from the graph that at small crack depths, the effects of the epoxy patches are negligible since the decrease in the natural frequency is also low. Figure 7 shows the increase in the natural frequency of the repaired beam in comparison to the unrepaired one. An increase of 31\% in the natural frequency is observed at $6 \mathrm{wt} . \% \mathrm{CNTs}$ and $e=0.2$. Also, a noticeable increase in the repairing takes place when $a / H$ goes above 0.5 .

Figure 8 shows the relative natural frequency but with different crack locations. The same is also observed here; the repair has no significant change in the crack locations that produce low decrease in the natural frequency of the beam, while at $e=0.2$, the relative natural frequency of the repaired beam increased with increasing CNTs wt.\%. Figure 9 shows the increase in natural frequency with different $e$ values; the higher the CNTs wt $\%$, the higher the increase in the natural frequency of the beam.

It is noticed from the graphs that increasing the contents of CNT in the epoxy matrix does not always cause a noticeable increase in the repair of the cracked beam natural frequency. Figure 10 shows the increase in the natural frequency of the cracked beam with different concentration ratios at $a / H=0.7, e=0.2, P_{L}=20 \mathrm{~mm}$, and $P_{t}=1.5 \mathrm{~mm}$. The graph shows that, after 4.0 wt.\% CNTs, the increase in the natural frequency converges to $31 \%$; further increase will cause no significant change in the natural frequency of the repaired beam. 


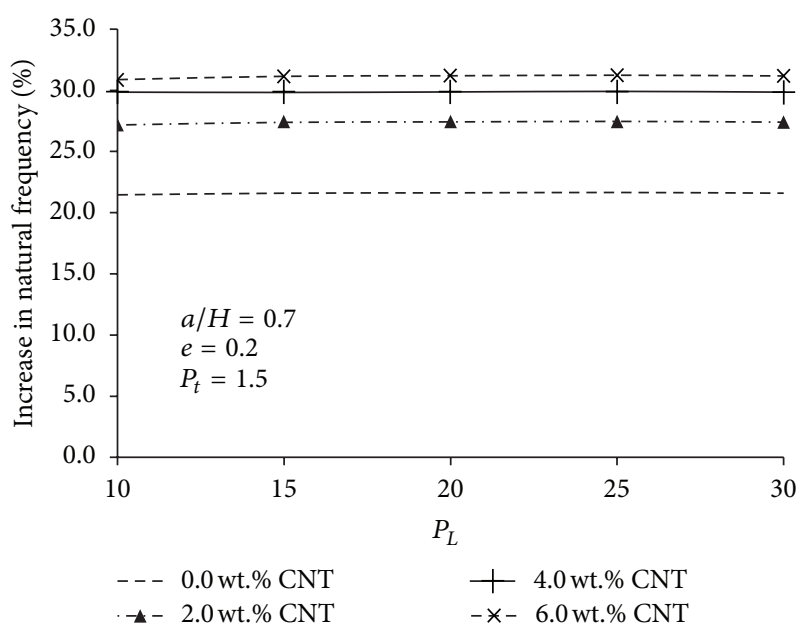

FIGURE 5: Increase in cracked beam natural frequency with different $P_{L}$ and wt.\% of CNT.

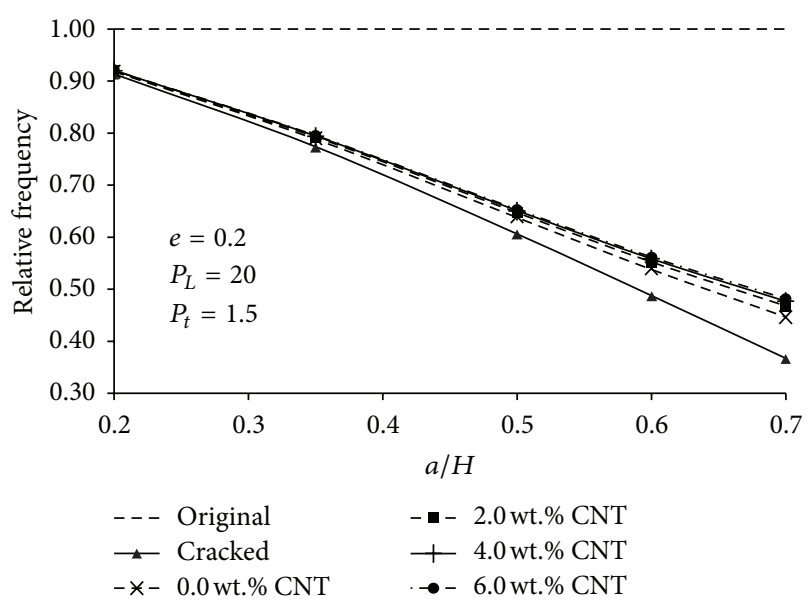

FIGURE 6: Relative natural frequency at different $a / H$ and wt.\% of CNT.

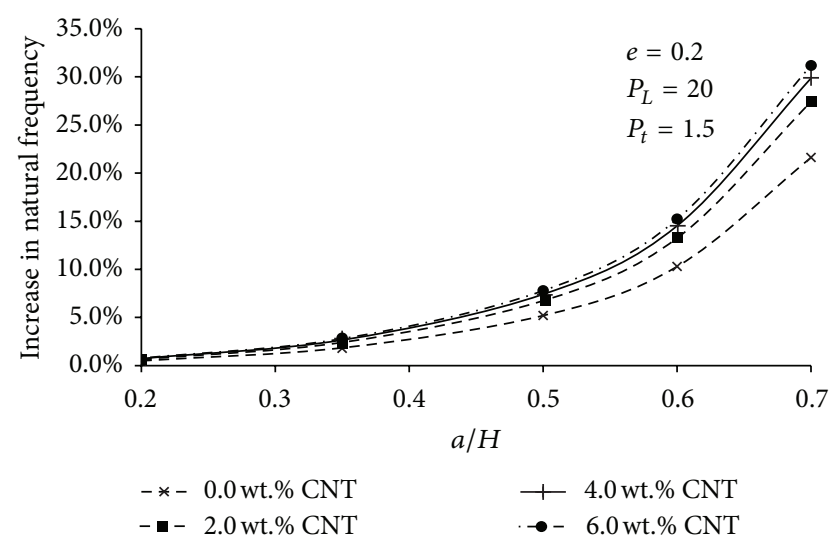

FIGURE 7: Increase in cracked beam natural frequency at different $a / H$ and wt.\% of CNT.

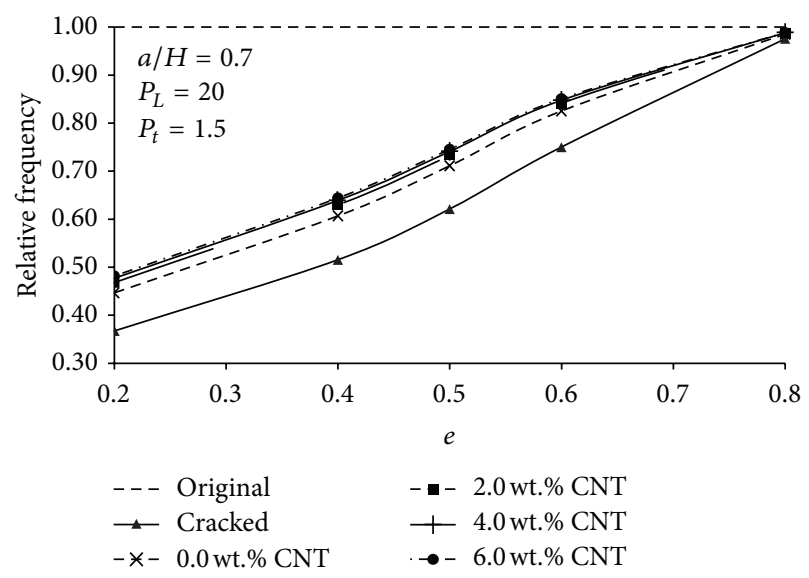

FIGURE 8: Relative natural frequency at different $e$ and wt.\% of CNT.

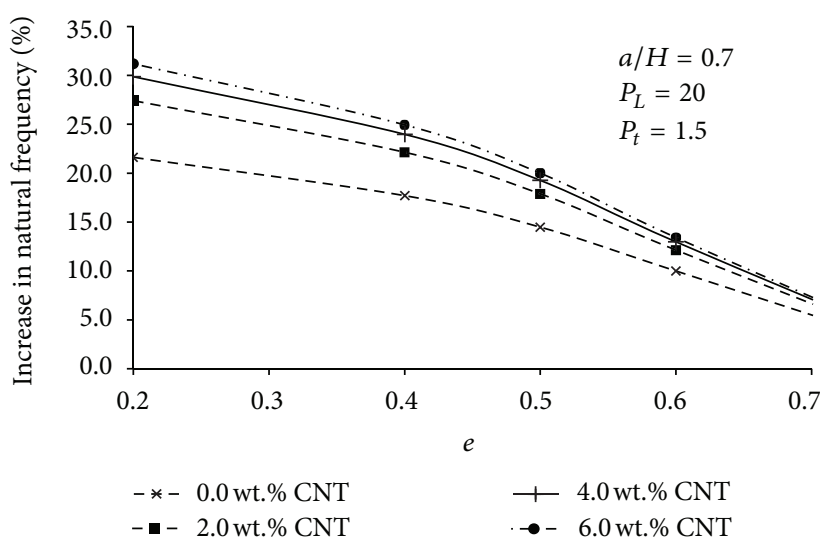

FIGURE 9: Increase in cracked beam natural frequency at different $e$ and wt.\% of CNT.

The present work is a start for more work on the repair of materials using CNT composite patches. In particular, the authors intend to conduct the following two studies.

(a) Experimental investigation of cracked specimens repaired by CNT composite patches to restore the natural frequency of the specimens. The CNT patch will be bonded over the crack location to repair it. The specimens will then be subjected to cyclic loadings to study the influence of the repair on the natural frequency. Different patch thickness and patch length values will be considered. In addition, different CNTs weight concentration ratios will be used. The facilities and equipment available at the Nanocenter of King Abdulaziz University will be used in this study.

(b) On the theoretical side, the authors will conduct further analysis on the stress intensity factor at the crack tip as was done by Bachir et al. [26] and will use the $J$-integral concept of Eshelby-Rice to add results for fractal cracks. The $J$-integral for a fractal is path dependent [27]. This is why a $J$-integral fractal should be the rate of release of potential energy per unit of measurement of the fractal crack growth [28]. The 


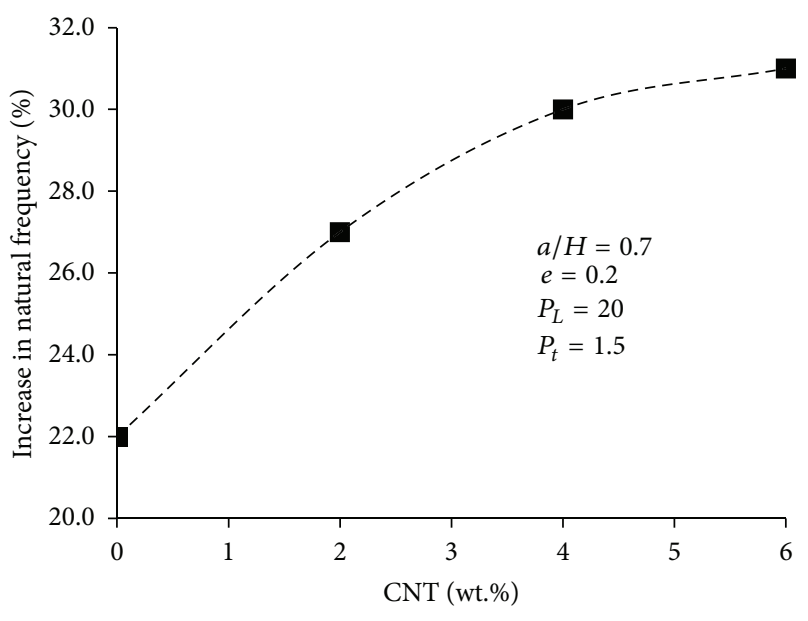

FIGURE 10: Increase in natural frequency with different CNT ratios.

authors also intend to compare how well will the CNT reinforced epoxy patches perform when compared with highly stiff composites such as carbon epoxy [29], boron epoxy [30, 31], and graphite epoxy [32].

\section{Conclusion}

A numerical FEA using ABAQUS/Standard was carried out to observe the repair of the natural frequency of a cracked steel cantilever beam with an adhesively bonded epoxy patch (with and without CNT reinforcement at different wt.\%). The first natural frequency was obtained for the original beam and then the natural frequency of the cracked beam $(a / H=$ 0.7 and $e=0.2$ ) with different $P_{t}$ and $P_{L}$ was obtained to determine the suitable values of $P_{t}$ and $P_{L}$. It is shown that $P_{L}$ has no effect on the repair of the natural frequency, while as $P_{t}$ increases, the natural frequency increases. The effect of $a / H$ and $e$ was investigated at $P_{t}$ and $P_{L}$ values of 1.5 and $20 \mathrm{~mm}$, respectively. The results show that the repair had insignificant effect on locations and depths that produced low decrease in the beam natural frequency no matter which CNT wt.\% was used. But at locations where there was a significant drop in the natural frequency, the effects of CNT's wt.\% became insignificant at concentrations more than $4.0 \mathrm{wt} . \%$. Further investigation can be carried out to see the effect of layered epoxy patches with different $P_{L}$ to reduce stress concentration when the patch thickness increases as in [8]. Experimental validation of the findings will be carried out in more details as the facilities and equipment are available for the authors. Further investigation will be done by inspecting the effects of the patches on the strain energy release rate at the crack tip which can be used as a supporting result on the claim of the effects of the epoxy patches.

\section{Acknowledgment}

This paper was funded by the Deanship of Scientific Research (DSR), King Abdulaziz University, Jeddah, under Grant no.
(21-135-D1432). The authors, therefore, acknowledge with thanks DSR technical and financial support.

\section{References}

[1] N. Khaji, M. Shafiei, and M. Jalalpour, "Closed-form solutions for crack detection problem of Timoshenko beams with various boundary conditions," International Journal of Mechanical Sciences, vol. 51, no. 9-10, pp. 667-681, 2009.

[2] J. T. Kim and N. Stubbs, "Crack detection in beam-type structures using frequency data," Journal of Sound and Vibration, vol. 259, no. 1, pp. 145-160, 2003.

[3] J. Lee, "Identification of multiple cracks in a beam using natural frequencies," Journal of Sound and Vibration, vol. 320, no. 3, pp. 482-490, 2009.

[4] D. Y. Zheng and N. J. Kessissoglou, "Free vibration analysis of a cracked beam by finite element method," Journal of Sound and Vibration, vol. 273, no. 3, pp. 457-475, 2004.

[5] J. A. Loya, L. Rubio, and J. Fernández-Sáez, "Natural frequencies for bending vibrations of Timoshenko cracked beams," Journal of Sound and Vibration, vol. 290, no. 3-5, pp. 640-653, 2006.

[6] S. Zhong and S. O. Oyadiji, "Analytical predictions of natural frequencies of cracked simply supported beams with a stationary roving mass," Journal of Sound and Vibration, vol. 311, no. 1-2, pp. 328-352, 2008.

[7] M. S. Matbuly, O. Ragb, and M. Nassar, "Natural frequencies of a functionally graded cracked beam using the differential quadrature method," Applied Mathematics and Computation, vol. 215, no. 6, pp. 2307-2316, 2009.

[8] H. Osnes, D. McGeorge, J. R. Weitzenböck, and G. O. Guthu, "Predicting failure of bonded patches using a fracture mechanics approach," International Journal of Adhesion and Adhesives, vol. 37, pp. 102-111, 2012.

[9] H. Hosseini-Toudeshky, M. Sadighi, and A. ojdani, "Effects of curing thermal residual stresses on fatigue crack propagation of aluminum plates repaired by FML patches," Compsite Structures, vol. 100, pp. 154-162, 2013.

[10] M. N. Nahas, "Experimental investigation of fatigue of cracked aluminum specimens repaired with fibre composite patches," Journal of Reinforced Plastics and Composites, vol. 11, no. 8, pp. 932-938, 1992.

[11] A. Ariaei, S. Ziaei-Rad, and M. Ghayour, "Repair of a cracked Timoshenko beam subjected to a moving mass using piezoelectric patches," International Journal of Mechanical Sciences, vol. 52, no. 8, pp. 1074-1091, 2010.

[12] E. N. Brown, S. R. White, and N. R. Sottos, "Retardation and repair of fatigue cracks in a microcapsule toughened epoxy composite. Part I: manual infiltration," Composites Science and Technology, vol. 65, no. 15-16, pp. 2466-2473, 2005.

[13] E. N. Brown, S. R. White, and N. R. Sottos, "Retardation and repair of fatigue cracks in a microcapsule toughened epoxy composite. Part II: in situ self-healing," Composites Science and Technology, vol. 65, no. 15-16, pp. 2474-2480, 2005.

[14] B. J. Blaiszik, N. R. Sottos, and S. R. White, "Nanocapsules for self-healing materials," Composites Science and Technology, vol. 68, no. 3-4, pp. 978-986, 2008.

[15] H. R. Williams, R. S. Trask, and I. P. Bond, "Self-healing sandwich panels: restoration of compressive strength after impact," Composites Science and Technology, vol. 68, no. 15-16, pp. 3171-3177, 2008. 
[16] S. Iijima, "Helical microtubules of graphitic carbon," Nature, vol. 354, no. 6348, pp. 56-58, 1991.

[17] K. I. Tserpes, P. Papanikos, G. Labeas, and S. G. Pantelakis, "Multi-scale modeling of tensile behavior of carbon nanotube-reinforced composites," Theoretical and Applied Fracture Mechanics, vol. 49, no. 1, pp. 51-60, 2008.

[18] M. M. Shokrieh and R. Rafiee, "Investigation of nanotube length effect on the reinforcement efficiency in carbon nanotube based composites," Composite Structures, vol. 92, no. 10, pp. 2415-2420, 2010.

[19] M. M. Shokrieh and R. Rafiee, "On the tensile behavior of an embedded carbon nanotube in polymer matrix with nonbonded interphase region," Composite Structures, vol. 92, no. 3, pp. 647-652, 2010.

[20] M. Kulkarni, D. Carnahan, K. Kulkarni, D. Qian, and J. L. Abot, "Elastic response of a carbon nanotube fiber reinforced polymeric composite: a numerical and experimental study," Composites Part B, vol. 41, no. 5, pp. 414-421, 2010.

[21] G. I. Giannopoulos, S. K. Georgantzinos, and N. K. Anifantis, "A semi-continuum finite element approach to evaluate the Young's modulus of single-walled carbon nanotube reinforced composites," Composites Part B, vol. 41, no. 8, pp. 594-601, 2010.

[22] S. K. Georgantzinos, G. I. Giannopoulos, and N. K. Anifantis, "Investigation of stress-strain behavior of single walled carbon nanotube/rubber composites by a multi-scale finite element method," Theoretical and Applied Fracture Mechanics, vol. 52, no. 3, pp. 158-164, 2009.

[23] M. Omidi, D. T. Hossein Rokni, A. S. Milani, R. J. Seethaler, and R. Arasteh, "Prediction of the mechanical characteristics of multi-walled carbon nanotube/epoxy composites using a new form of the rule of mixtures," Carbon, vol. 48, no. 11, pp. 32183228, 2010.

[24] H. Rokni, A. S. Milani, and R. J. Seethaler, "Maximum natural frequencies of polymer composite micro-beams by optimum distribution of carbon nanotubes," Materials and Design, vol. 32, no. 6, pp. 3389-3398, 2011.

[25] H. Rokni, A. S. Milani, and R. J. Seethaler, "2D optimum distribution of carbon nanotubes to maximize fundamental natural frequency of polymer composite micro-beams," Composites Part B, vol. 43, no. 2, pp. 779-785, 2012.

[26] B. Bachir Bouiadjra, W. Oudad, A. Albedah, F. Benyahia, and M. Belhouari, "Effects of the adhesive disband on the performances of bonded composite repairs in aircraft structures," Materials and Design, vol. 37, pp. 89-95, 2012.

[27] A. Yavari, S. Sarkani, and E. T. Moyer Jr., "The mechanics of self-similar and self-affine fractal cracks," International Journal of Fracture, vol. 114, no. 1, pp. 1-27, 2002.

[28] X. J. Yang, Advanced Local Fractional Calculus and Its Applications, World Science Publisher, New York, NY, USA, 2012.

[29] R. Chandra and K. Guruprasad, "Numerical estimation of stress intensity factors in patched cracked plates," Engineering Fracture Mechanics, vol. 27, no. 5, pp. 559-569, 1987.

[30] S. M. Fekih, A. Albedah, F. Benyahia, M. Belhouari, B. Bachir Bouiadjra, and A. Miloudi, "Optimisation of the sizes of bonded composite repair in aircraft structures," Materials and Design, vol. 41, pp. 171-176, 2012.

[31] H. Hosseini-Toudeshky, B. Mohammadi, and H. R. Daghyani, "Mixed-mode fracture analysis of aluminium repaired panels using composite patches," Composites Science and Technology, vol. 66, no. 2, pp. 188-198, 2006.
[32] M. R. Ayatollahi and R. Hashemi, "Computation of stress intensity factors (KI, KII) and T-stress for cracks reinforced by composite patching," Composite Structures, vol. 78, no. 4, pp. 602-609, 2007. 


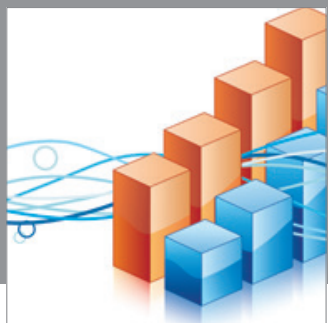

Advances in

Operations Research

mansans

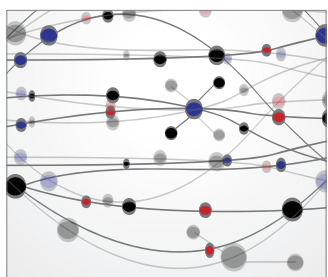

The Scientific World Journal
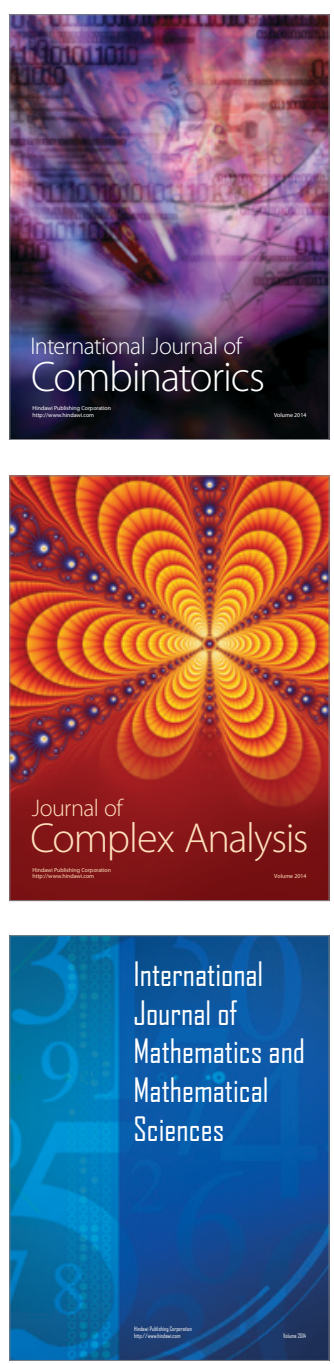
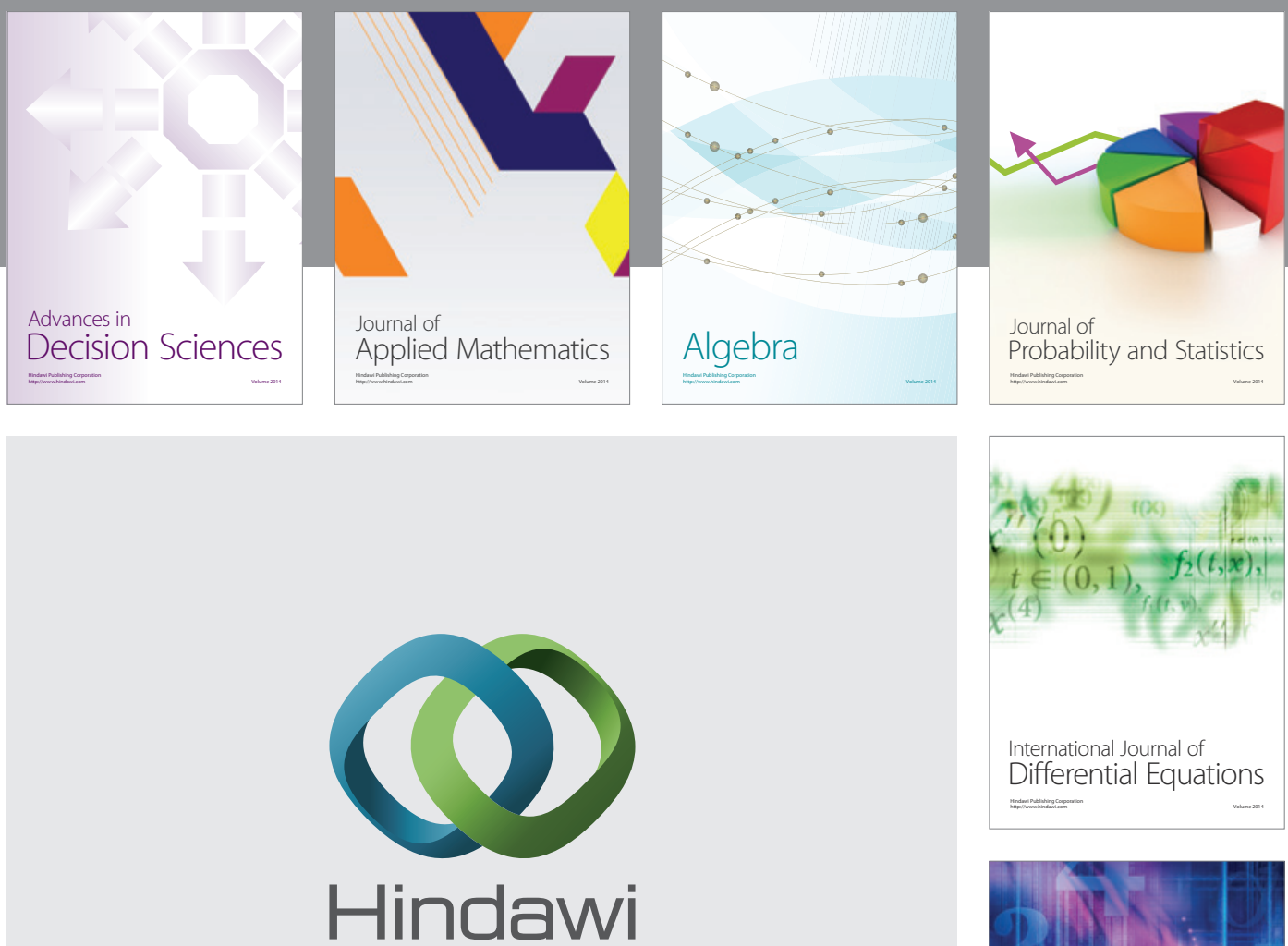

Submit your manuscripts at http://www.hindawi.com
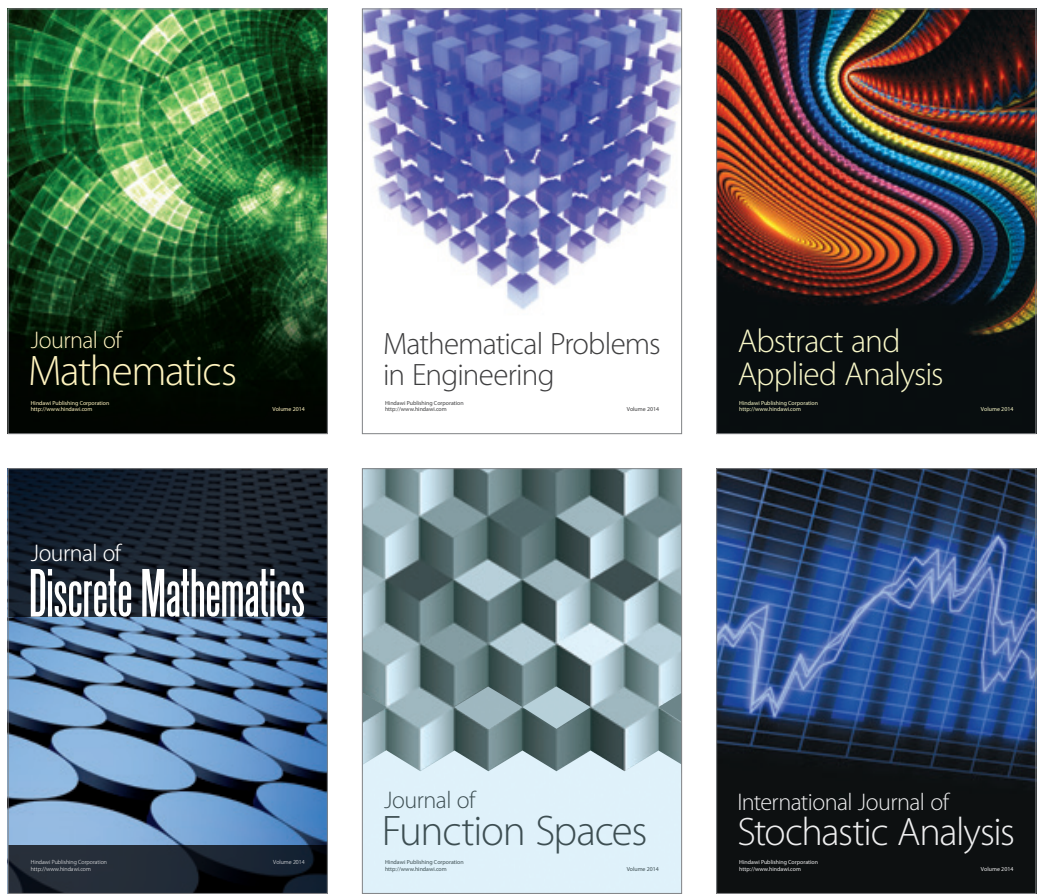

Journal of

Function Spaces

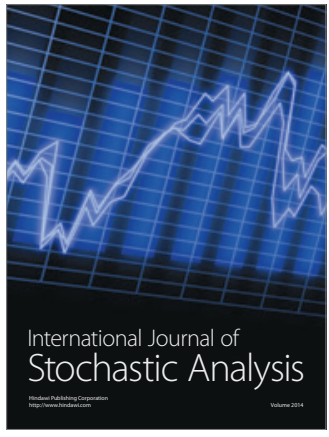

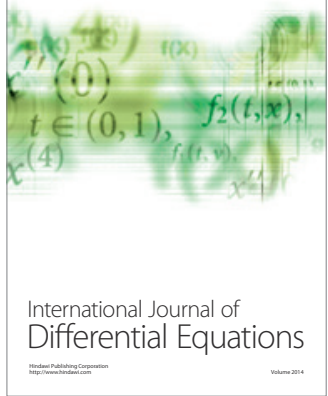
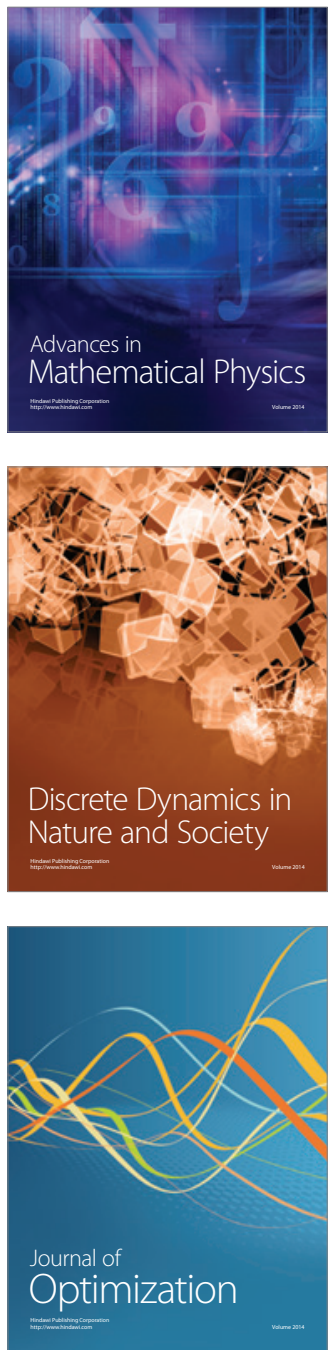